\title{
Research on deformation of submarine slope in Zhoushan Islands by in-situ observation
}

\author{
Tianyang Liang ${ }^{1}$, Liang Xue ${ }^{1}$, Yankai Hou ${ }^{1}$, Hong Zhang ${ }^{1}$, and Hongxian Shan ${ }^{1,2, *}$ \\ ${ }^{1}$ Institute of Environmental Science and Engineering, Ocean University of China, Qingdao, Shandong, China \\ ${ }^{2}$ The Key Laboratory of Marine Environment and Ecology, Ministry of Education (Ocean University of China), Qingdao, Shandong, China
}

\begin{abstract}
Instability of submarine slopes in Zhoushan Islands is widespread. Frequent submarine landslides pose a great threat to offshore facilities such as submarine optical cables, reclamation projects, ports and docks. In this paper, a self-developed in-situ observation system is used to observe the deformation of submarine slopes on the southwest side of Zhujiajian Island in Zhoushan Islands for 75 days. The results show that the deformation characteristics of sediments at different depths of the submarine slope are different, and the lateral deformation of bottom sediments is about $0.75 \mathrm{~mm}$, which is three times as much as the deformation of overlying sediments. The deformation process presents a step-like change, and the deformation direction is consistent with the trend of submarine slope.
\end{abstract}

\section{Introduction}

Zhoushan Islands, located in the south of Hangzhou Bay Estuary, is the gathering place of large ports in China, and its strategic position is very important [1]. Frequent submarine landslides pose a great threat to coastal engineering facilities such as submarine optical cables, ports and docks [2]. More and more attention have been paid to the research on the mechanism of submarine landslide. At present, the investigation and study of submarine landslide mainly relies on marine geophysical detection technologies such as multi-beam sounding and shallow profile technology [3-4]. The occurrence process and triggering factors of landslide can only be known by speculation [5]. In contrast, the submarine in-situ observation technology can obtain more time-sensitive observation data, which is more conducive to the study of the mechanism and evolutionary process of submarine landslides [6].

Prior et al.[7] used the sediment dynamic observation device to record the acceleration value and dip angle change, and found the revival phenomenon of submarine landslide induced by storm surge in the underwater delta of the Yellow River. Blum et al.[8] used the submarine acoustic measurement system to monitor the unstable slope of seabed for the first time. Urlaub et al.[9] used acoustic measurement system and pressure gauge to capture the sliding deformation process of Etna volcano flank. Wang et al.[10] successfully captured the seabed deformation process induced by storm surge in the underwater delta of the Yellow River by using the submarine landslide monitoring system (SLM), and put forward the mechanism of seabed instability caused by waves in the underwater delta of the Yellow River [11].
In this paper, a self-developed in-situ observation system for monitoring deformation of marine sediments is used to observe the submarine slope in the southwest of Zhujiajian Island in Zhoushan Islands for 75 days. Observation data such as lateral deformation and deformation direction of potential sliding surface of submarine slope are obtained for the first time. The successful application of this observation provides a new technical means for the identification and monitoring of potential sliding surfaces of submarine slopes.

\section{In-situ observation of submarine slope}

\subsection{In-situ observation system}

The in-situ observation system for monitoring deformation of marine sediments is composed of array displacement meter, data acquisition and transmission system and power supply system. It can realize real-time observation of vertical deformation and lateral deformation of seabed sediments at different depths (Fig.1a). The core component of deformation observation is array displacement meter, which is composed of several rigid measuring units of equal length. The measuring units are connected in parallel through a bus structure, which can bend in any direction, but can resist torsional motion (Fig.1b). A high-precision MEMS accelerometer is integrated into a measurement unit, and the bending angle and direction of each observation node are obtained by sensing the change of acceleration field [12]. The array displacement meter has a built-in microprocessor, which can calculate the deformation of each observation unit (Fig.1c). 


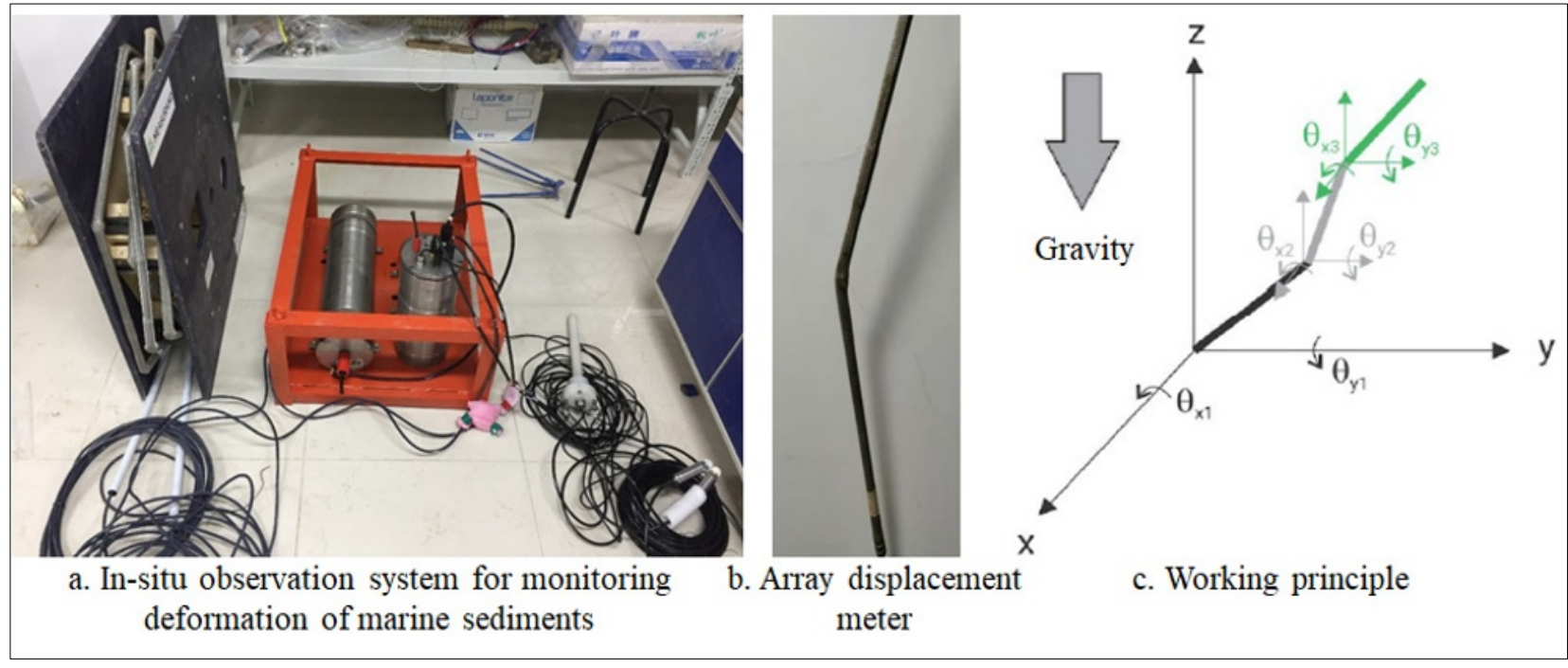

Fig.1. In-situ observation system and its working principle

\subsection{Observation area}

The observation area is located on the northeast slope of tidal current scouring trough in the southwest of Zhujiajian Island, Zhoushan Islands, Zhejiang Province, China (Fig.2). This area belongs to a typical tidal channel development area, with criss-crossing tidal channels, and many submarine landslides [13-14]. The tidal category in the observed sea area is regular semidiurnal tide, with an average tidal range of $2.5 \sim 2.8 \mathrm{~m}$ and a maximum tidal range of $4.79 \mathrm{~m}$. Waves are mainly caused by wind, and big waves are mostly caused by windy weather. The annual average wave height is $0.1 \mathrm{~m}$, and the main wave direction is southerly [15-16].

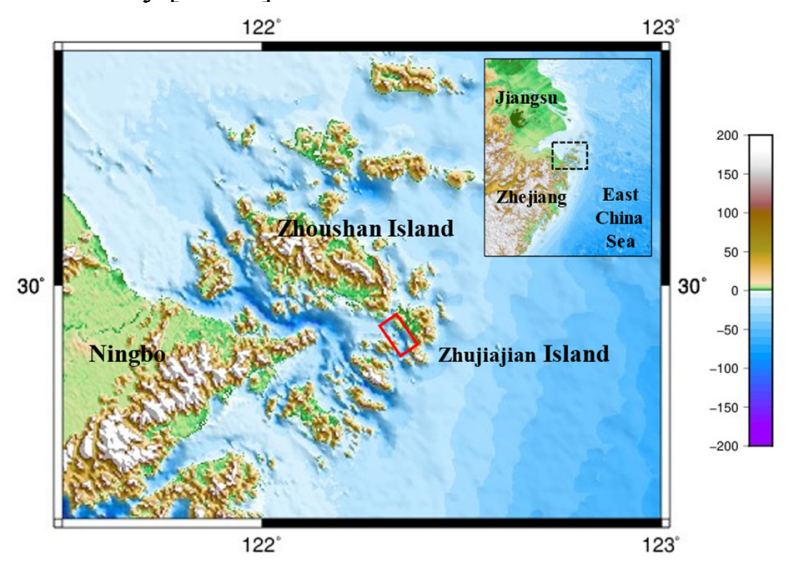

Fig.2. Geographic location of the observation area

Combined with geophysical survey data such as shallow stratum profile, it can be found that the terrain in the observation area is high in the northeast and low in southwest. There are many obvious sediment stratification interfaces on the submarine slope, which are potential sliding surfaces for deformation and instability of the submarine slope. The coordinates of observation points selected in this paper are $2954^{\prime} 16.5855^{\prime \prime} \mathrm{n}$ and $12220^{\prime}$ 41.2655 " e. The water depth of the observation point is about $10-12 \mathrm{~m}$, and the local terrain is flat with an average slope of 8-9 degree, which is beneficial to the deployment and recovery of the observation system. There is an obvious sediment interface about $13 \mathrm{~m}$ below the seabed surface where the observation point is located, as shown in Figure 3.

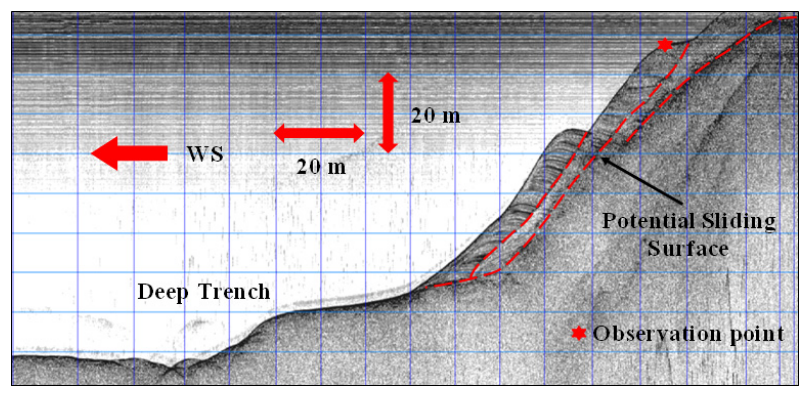

Fig.3. Location of observation point and shallow seismic profile

\subsection{Method and process}

In order to obtain the sediment deformation process at the potential sliding surface of the submarine slope, array displacement meters $(6 \mathrm{~m})$ are arranged in the range of about $7.5 \mathrm{~m}$ to $13.5 \mathrm{~m}$ under the seabed through offshore drilling. A pore water pressure monitoring system and a hydrodynamic observation platform are simultaneously arranged within $10 \mathrm{~m}$ around the borehole. The total length of the piezometer probe is $7 \mathrm{~m}$, which is arranged by gravity penetration. The hydrodynamic observation platform is equipped with wave\&tide reorder, Acoustic Doppler Profiler, data acquisition cabin and other equipment.

The whole system can realize the synchronous acquisition of deformation data of potential sliding surface, pore water pressure of seabed sediments and field hydrodynamic parameters. The specific observation scheme is shown in Figure 4. 


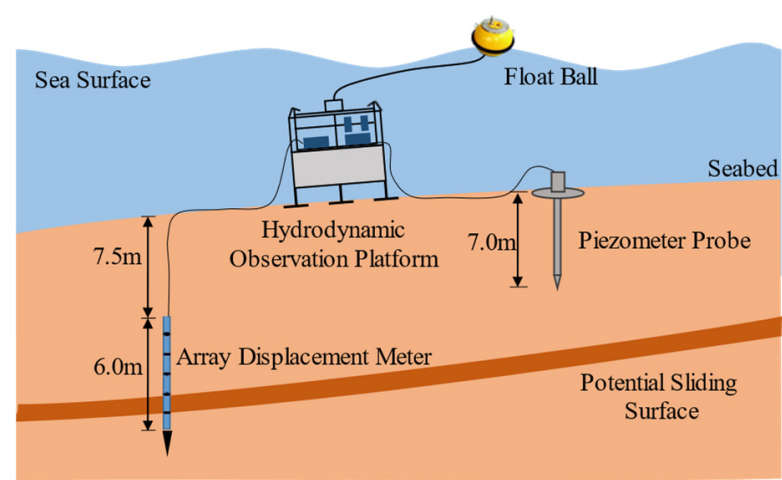

Fig.4. Schematic diagram of observation scheme

\section{Results and discussion}

The observation started on August 29th, 2019 and ended on October 7th, 2019. The lateral deformation data of sediments at different depths of submarine slope, the pore pressure response of sediments, and the data of velocity and wave height in the observation area are successfully obtained. This paper focuses on the analysis of lateral deformation characteristics of sediments at different depths, including deformation value, deformation direction and deformation process.

\subsection{Deformation value}

Selecting the observation data on August 29th, 2019 as the benchmark for analysis and calculation. Fig. 6 shows the lateral deformation of sediments at different depths on the submarine slope within 75 days obtained by the in-situ observation system. The sediments in the depth range of $12 \mathrm{~m}-13.5 \mathrm{~m}$ below the seabed surface are laterally deformed, and the deformation process is obvious, with a cumulative deformation of $0.7 \mathrm{~mm}$. There is no obvious deformation of sediments in the range of $9.5 \mathrm{~m}-12 \mathrm{~m}$ below the seabed surface, and the accumulated deformation is about $0.25 \mathrm{~mm}$. The sediments in the range of $7.5 \mathrm{~m}-9.5 \mathrm{~m}$ below the seabed surface have undergone several lateral deformation processes, with the cumulative deformation of $1.25 \mathrm{~mm}$.

According to the value of deformation, the sediments in the observation range can be divided into three parts: the upper part (7.5 m-9.5 m below the seabed surface), the middle part ( $9.5 \mathrm{~m}-12.0 \mathrm{~m}$ below the seabed surface) and the bottom part ( $12.0 \mathrm{~m}-13.5 \mathrm{~m}$ below the seabed surface). The bottom part is located at the potential sliding surface of the submarine slope.

The deformation value of sediment in the middle part is about $20 \%$ of the sediment in upper part and $35 \%$ of the sediment in bottom part, which can be regarded as the deformation of sediment in stable state. It can be seen that the deformation of sediment at the potential sliding surface is larger than that of the middle part, and the deformation process of sediment is more obvious than that of the upper part.

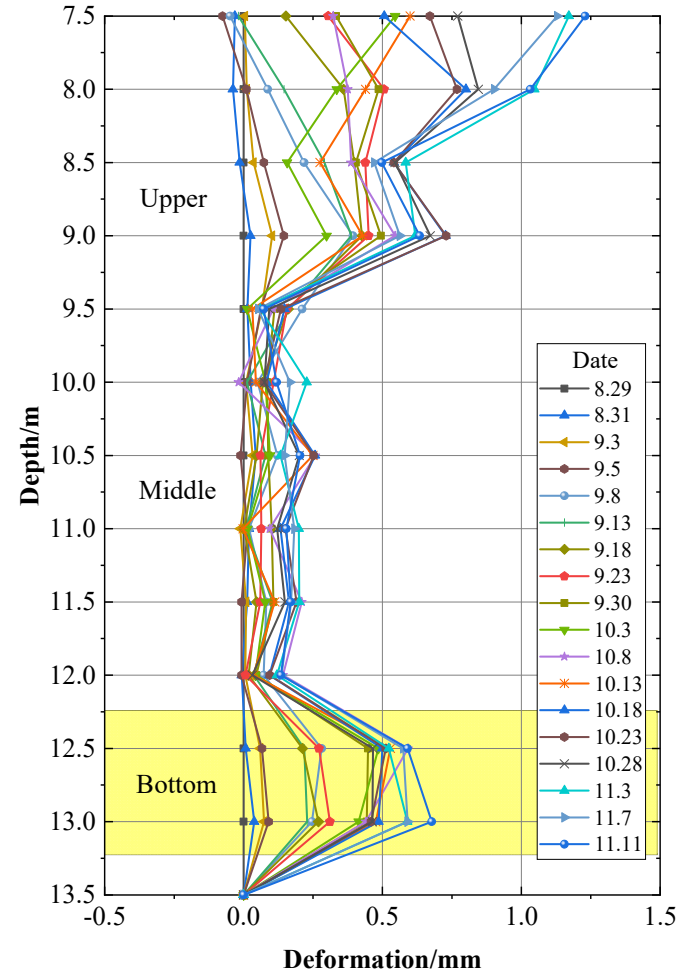

Fig.5. Lateral deformation of sediments at different depths

\subsection{Deformation direction}

By projecting the deformation data obtained by array displacement meter along its $x-y$ plane, the movement track of sediment lateral deformation can be obtained (Fig.6). The $\mathrm{x}$-axis direction corresponds to the east direction of the geographical orientation, and the y-axis direction corresponds to the north direction of the geographical orientation, so the deformation direction can be judged according to the motion trajectory.
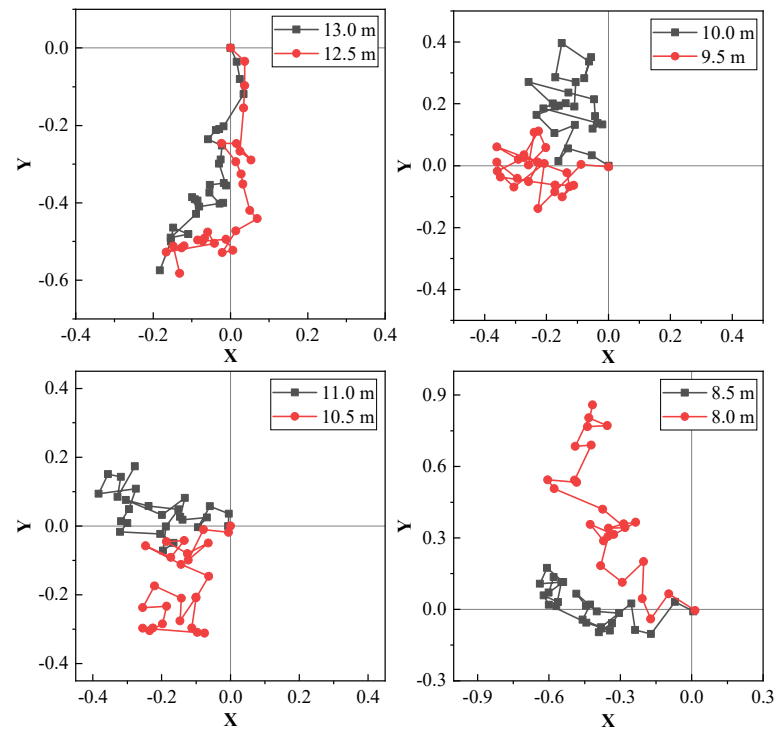

Fig.6. Track of lateral deformation of sediments

The lateral deformation direction of sediments with different depths is different, and the deformation direction changes counterclockwise from bottom part to upper part. 
The main deformation direction of upper and middle sediments is west, which is consistent with the tidal current direction in the observation area. The deformation direction of sediments on the bottom potential sliding surface ( $12.5 \mathrm{~m}-13 \mathrm{~m}$ below the seabed surface) is obvious, and the main direction is southwest, which coincides with the overall trend of the submarine slope. The coincidence of deformation directions further indicates that the submarine slope is easier to slide along it.

\subsection{Deformation process}

Select the deformation data of sediments at the upper $8 \mathrm{~m}$, middle $11 \mathrm{~m}$ and bottom $13 \mathrm{~m}$ to draw the lateral deformation process map. It can be clearly seen that the starting time and duration of the deformation process are different (Fig.7). For example, in the process a, the bottom sediment is deformed first, the upper sediment is deformed after 6 days, and the middle sediment is not deformed (Fig.7a). However, in the process c, the upper sediment and the middle sediment are greatly deformed at the same time, and no deformation occurs at the bottom sediment (Fig.7c). Although there is a large deformation process in the upper part and middle part, most of them are elastic changes, and no obvious lateral cumulative deformation occurs like the bottom part (Fig.7b). The reason is that the upper sediment is more susceptible to hydrodynamic action, which causes the fluctuation of deformation.

In addition, the sediment at the potential sliding surface presents the characteristic of step change during multiple deformation processes (Fig.7d). This obvious lateral deformation process and large deformation amount will create good sliding conditions for submarine landslide.

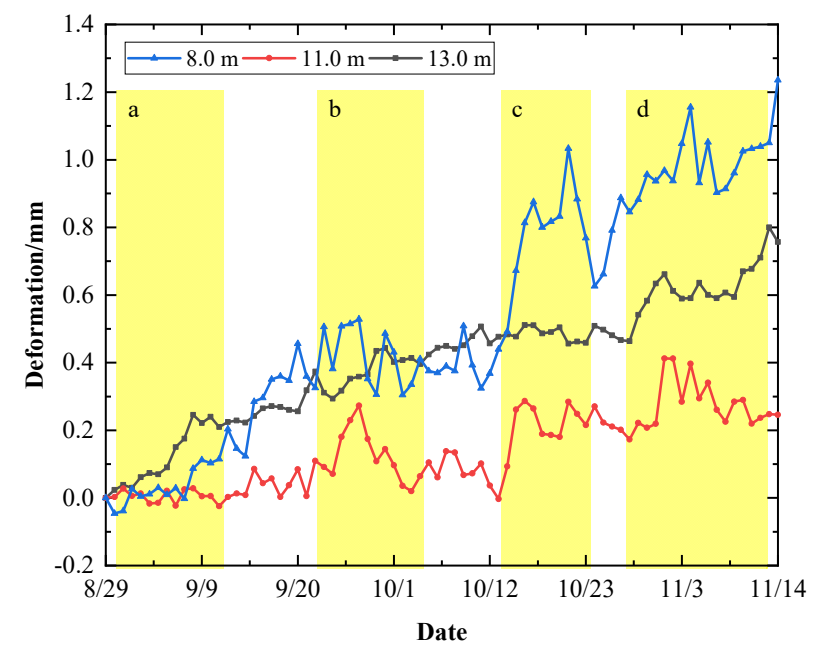

Fig.7. Lateral deformation process of upper, middle and bottom sediments

\section{Conclusions}

In this paper, a self-developed observation system is used to carry out in-situ observation for 75 days, and the lateral deformation data of sediments at different depths of the submarine slope are successfully obtained. The main conclusions are as follows:

(1) There are significant differences in the lateral deformation characteristics of sediments at different depths in the observation area. The maximum lateral deformation is about $1.25 \mathrm{~mm}$.

(2) The lateral deformation of sediments at the potential sliding surface is about $0.7 \mathrm{~mm}$, which is close to 3 times of the overlying sediments. And the lateral deformation direction coincides with the overall trend of submarine slope.

(3) The deformation process of sediments at the potential sliding surface presents a step change, where sediments are more prone to lateral deformation.

\section{Acknowledgements}

This work is supported by the project of National Natural Science Foundation of China (41877223): Research on initiation process and controlling factors of submarine landslide in Yellow River underwater delta based on insitu observation.

\section{References}

1. D.J. Liu, T.J. Hu, P.Y. Huang, Transactions of Oceanology and Limnology, 3, 153-160, (2014)

2. H.C. Sun, T.L. Cai, X.M Xia, JOURNAL OF SCIENCES, 37, 59-66, (2019)

3. M. Vanneste, N. Sultan, S. Garziglia, Marine Geology, 352, 183-214, (2014)

4. C.Q. Zhu, Y.G. Jia, X.L. Liu, Marine Geology \&Quaternary Geology, 35, 153-163, (2015)

5. Y.G. Jia, Z.H. Wang, X.L. Liu, Periodical of Ocean University of China, 47, 61-72, (2017)

6. M. Zhang, Y. Huang, Y. Bao, Natural Hazards, 81, 1373-1383, (2016)

7. D.B. Prior, J.N. Suhayda, N.Z. Lu, Nature, 341, 4750, (1989)

8. J.A. Blum, C.D. Chadwell, N. Driscoll, GEOPHYS RES LETT, 37, 438-454, (2010)

9. U. Morelia, P. Florian, G. Felix, B. Alessandro, Science Advances, 4, (2018).

10. Z.H. Wang, Y.G. Jia, X.L. Liu, Bulletin of Engineering Geology and the Environment, 77, 10911102, (2018)

11. Z.H. Wang, Y.F. Sun, Y.G. Jia, Landslides, 17, 18491862, (2020)

12. H. Chen, Y.J Li, R. Fang, Chinese Journal of Rock Mechanics and Engineering, 34, 4063-4070, (2015)

13. X.H Lai, Y.C Ye, Q.C Xie, Marine Geology \& Quaternary Geology, 2, 45-50, (2000)

14. Y.F. Liu, X.M. Xia, J.J. Jia, HAIYANG TONGBAO, 6, 53-60, (2007)

15. H.D. Chen, Q.S. Yan, L.S. Xiang, Journal of East China Normal University (Natural Sciences), 2, 7791, (1982)

16. C.Y. Zhang, S.L. Yang, X.X. Luo, SHANGHAI LAND \& RESOURCES, 33, 39-43, (2012) 